\title{
EDITORIAL
}

\section{Maternal mortality: more than just anecdotal evidence}

\section{Journal of Perinatology (2007) 27, 595-596; doi:10.1038/sj.jp.7211817}

In 2004, there were 540 maternal deaths in the United States; the rate of 13.1 per 100,000 births is the highest recorded in recent years. ${ }^{1}$ This means that this many obstetric providers, hospital staffs and families have a devastating anecdotal experience. As described by Gawande, ${ }^{2}$ this number has dropped dramatically over the past century due to antibiotics, blood banking and uterotonic agents, but we can still do better. These events can be carefully examined for mistakes including clinician error, systems inefficiencies and patient education in order to avoid them in the future. However, stories cannot be systematically examined for predictors of these untoward events; for that we need epidemiologic methodology.

In the current edition of the Journal of Perinatology, Goffman et al. present a case-control study of maternal mortalities and near-miss events and examine some of these associated characteristics. Near-miss events have been used in this area of perinatal epidemiology in order to increase the statistical power to better identify both predictive characteristics and medical management that may be associated with maternal mortality. While there is some debate in the literature about how to define such near-miss events, those chosen by the authors of current paper included admission to the ICU, emergent hysterectomy, cardiac arrest and anoxic events are all circumstances or events that are likely to be strongly associated with maternal mortality.

Interestingly, these authors identified several important characteristics that were associated with mortality or near-miss events: maternal obesity, history of a prior cesarean and AfricanAmerican race or Hispanic ethnicity. With respect to maternal obesity, it is associated with various complications in pregnancy, including gestational diabetes, pre-eclampsia, macrosomia, cesarean delivery and stillbirth. ${ }^{3-6}$ Thus, it is not particularly surprising that it is also associated with these near-miss events. What is concerning, however, is that since the increasing prevalence of obesity in the population has increased the number of obese pregnant women as well, ${ }^{7}$ the number of mortality and severe morbidity events will likely increase. For example, if we consider that the prevalence of maternal obesity has doubled in recent years, then using these authors' findings of an odds ratio (OR) of 3 , the number of maternal mortality events would increase from 300 to 400 annually and the number of near-miss events would increase by a similar proportion.

With respect to prior cesarean delivery, from the recent paper by Silver et al., which found higher rates of previa, accreta and hysterectomy with increasing number of prior cesareans, it is not surprising that maternal morbidity and associated mortality will rise in these women as well. Further, with the rate of cesarean delivery recently reaching $30.2 \%$, ${ }^{9}$ the number of women who will have had a prior cesarean is also increasing. Again, this is likely to be associated with higher rates of such near-miss and mortality events.

In terms of the findings of higher events noted among women of African-American race or Hispanic ethnicity, the first causal culprit usually suspected is socioeconomic status, which leads to later onset and less prenatal care. But, even when these authors controlled for both educational level and insurance status, these racial/ethnic differences persisted. Further, inadequate prenatal care itself only made a small statistically nonsignificant difference in near-miss or mortality events. It may be that there is some contribution from actual differences in obstetric complications such as pre-eclampsia, which is higher among African-American women, ${ }^{10}$ and gestational and type II diabetes, which is higher among Hispanic women. ${ }^{11}$ However, these differences are unlikely to account for the entire difference in these authors' findings of ORs of 7 for AfricanAmerican women and 4 in women of Hispanic ethnicity. Moreover, a recent study demonstrated that even in the setting of complications of pregnancy, there was a higher per case fatality rate among AfricanAmerican women as compared to white women. ${ }^{12}$

Thus, to capsulize the importance of these authors' findings, two of our patient characteristics, obesity and prior cesarean delivery, both appear to increase mortality and near-miss events. Both of these characteristics are on the rise and deserve immediate attention to ameliorate this increase and possibly reverse the trend. However, with respect to obstetric outcomes and race/ethnicity, further thoughtful investigation into the causal relationship between these two needs to be made. Without understanding why and how characteristics like race/ethnicity and socioeconomic factors lead to morbidity and mortality, we will be unable to reduce the inherent disparities that persist in our obstetric outcomes.

AB Caughey

Department of Obstetrics, Gynecology and Reproductive Sciences, University of California, San Francisco, San Francisco,

CA, USA

E-mail: abcmd@berkeley.edu

\section{References}

1 Minino AM, Heron MP, Murphy SL, Kochanek KD. Deaths: final data for 2004 . Natl Vital Stat Rep 2007; 55(19): 1-120. 
2 Gawande A. Better. Metropolitan Books: New York, NY, 2007 pp 169-200.

3 Rosenberg TJ, Garbers S, Chavkin W, Chiasson M. Prepregnancy weight and adverse perinatal outcomes in an ethnically diverse population. Obstet Gynecol 2003; 102 : $1022-1027$.

4 Cnattingius S, Bergstrom R, Lipworth L, Kramer MS. Prepregnancy weight and the risk of adverse pregnancy outcomes. $N$ Engl J Med 1998; 338: 147-152.

5 Nohr EA, Bech BH, Davies MJ, Frydenberg M, Henriksen TB, Olsen J. Prepregnancy obesity and fetal death: a study within the Danish National Birth Cohort. Obstet Gynecol 2005; 106: 250-259.

6 Ramos GA, Caughey AB. Interrelationship between ethnicity and obesity on obstetrical outcomes. Am J Obstet Gynecol 2005; 193: 1089-1093.

7 Hedley AA, Ogden CL, Johnson CL, Carroll MD, Curtin LR, Flegal KM. Prevalence of overweight and obesity among US children, adolescents, and adults, 1999-2002. JAMA 2004; 291: 2847-2850.
8 Silver RM, Landon MB, Rouse DJ, Leveno KJ, Spong CY, Thom EA et al. Maternal morbidity associated with multiple repeat cesarean deliveries. Obstet Gynecol 2006; 107(6): 1226-1232

9 Hamilton BE, Martin JA, Ventura SJ. Births: preliminary data for 2005. Natl Vital Stat Rep 2006; 55(11): 1-18

10 Caughey AB, Stotland NE, Washington AE, Escobar GE. Maternal ethnicity, paternal ethnicity, and parental ethnic discordance: predictors of preeclampsia. Obstet Gynecol 2005; 106: 156-161

11 Esakoff TF, Cheng YW, Caughey AB. What is the optimal threshold to screen for gestational diabetes among different ethnicities? Am J Obstet Gynecol 2005; 193 $1040-1044$

12 Tucker MJ, Berg CJ, Callaghan WM, Hsia J. The Black-White disparity in pregnancyrelated mortality from 5 conditions: differences in prevalence and case-fatality rates. Am J Public Health 2007; 97(2): 247-251. 